\title{
How game features give rise to altruism and collective action? Implications for cultivating cooperation by gamification
}

\author{
Marc Riar \\ IKM, Technical \\ University of Berlin \\ $\underline{\text { marc.riar@tu-berlin.de }}$
}

\author{
Benedikt Morschheuser \\ IISM, Karlsruhe \\ Institute of Technology \\ benedikt.morschheuser \\ @kit.edu
}

\author{
Juho Hamari \\ Gamification Group \\ Tampere University \\ juho.hamari@tuni.fi
}

\author{
Rüdiger Zarnekow \\ IKM, Technical \\ University of Berlin \\ ruediger.zarnekow@tu- \\ berlin.de
}

\begin{abstract}
Due to the general gamification of our culture and society as well as the proliferation of games in our everyday activities, people are increasingly looking at games and gamification as a source for cooperation and other prosocial behaviors. However, not all game features lead to increased cohesion, cooperation or collaboration between people. While some games indeed are geared for cooperation, majority of games also aim toward competition or just non-social activity. Therefore, a prominent research problem exists in understanding how different game and gamification design may lead to altruistic sentiment and collective action. In this study, we investigated how the engagement with cooperative game features relates to the emergence of altruism and whether altruism leads to the formation of we-intentions in a gaming context. We employed data gathered among players of the augmented reality game Ingress $(N=206)$ and analyzed the data using PLS-SEM. The results show that game features can give rise to altruism and that altruism can invoke we-intentions via cooperative goal structures (we-goals) of individuals. In addition to providing important insights regarding how cooperation emerges within games, this study provides implications for cultivating cooperation by gamification.
\end{abstract}

\section{Introduction}

Cooperation and altruistic action are key prosocial behaviors in our society and pivotal for a number of desirable outcomes, such as engagement in charitable work, social support, increased cohesion as well as increased productivity within teams and better organizational performance [17][25][26][45]. It seems therefore evident why cooperation and altruistic action are in great demand, not only in our society but also in organizational contexts and why explaining such behaviors has been an aspiration of scholars for many years [6][11][13][25][26]. Of late, the seemingly effortless emergence of cooperative and altruistic activity in multiplayer online games has come to the attention of scholars [14][18][19][43] and with that an increasing interest in how cooperative game patterns may be utilized outside of games (i.e. as a form of gamification) [30][37][38][39][40]. Gamification has been a soaring trend in recent years [23][24]. It refers to transforming systems, services and activities to afford similar positive experiences and skills as games do (i.e. gamefulness), often against the backdrop of increasing user engagement or motivating (beneficial) behavioral outcomes [12][22][24].

However, so far, little is known about how and which game features give rise to altruism and cooperation in games and thus there is still a lack of understanding how cooperative potentials of games could be used outside of a gaming context [7][29]. Current gamification literature has pointed out that much focus has been set on exploring individualistic motivations and that considerably less research has been conducted to examine collective perspectives of gamification [7][29][40]. Since games and gamification have become increasingly relevant for organizational contexts [33][54], it seems vital to explore any untapped potentials regarding design characteristics that could support collective activity in settings such as in computer supported collaborative work (CSCW) and learning (CSCL) environments.

One theory that has drawn much attention in terms of explaining cooperation in technological settings and online communities is we-intention theory (e.g. [2][3][4][5][49][50][51][52]). In contrast to the more commonly employed individual intention schemes, weintention theory relies on the notion that individuals do not perceive themselves as isolated actors contributing to a group performance independently, but rather as a part of a collective acting together to achieve mutually held goals [2][50][51][52]. There have been suggestions in cooperation theory that altruism may play a central role for the formation of we-intentions [2][50], 
however, empirical evidence of this thesis remains scarce. In addition to closing an important gap by investigating how game features can give rise to altruism and cooperation, it would present a vital contribution to we-intention research to explore the pending theoretical issue pertaining to the role of altruism for the formation of we-intentions.

The purpose of this study is therefore to empirically investigate whether the interaction with cooperative game features leads to the emergence of altruism and if altruism may be responsible for invoking we-intentions in a gaming context. In addition, based on the results, we seek to provide implications for cultivating cooperation by gamification. In order to answer our research question, we employ data from a questionnaire conducted with players of the augmented reality game Ingress $(n=206)$. This study provides relevant insights by discussing how games give rise to altruism and cooperation and by presenting important implications for the design of gamified systems that seek to increase altruistic and cooperative activity.

\section{Theoretical background}

\subsection{We-intention}

Cooperation is widely characterized as involving two or more individuals working together to accomplish mutual goals [26]. The notion behind two individuals or a group of people working together and having overlapping goals has encouraged researchers to rethink how intentions must unfold in such situations as compared to ones in which a person follows personal goals and acts individually. Thus, it has previously come to the understanding of some scholars that the dissimilar situations of an individual acting alone or an individual acting together with others calls for different conceptualizations with respect to how intentions emerge. This led to the birth of we-intention theory [50][51][52].

Tuomela [50][51][52] theorizes that pure cooperation is characterized by the presence of we-intentions among the cooperating individuals. According to the theory, the concept of we-intentions involves at least two individuals who have common goals and collective intentions that can be expressed as "We will perform $\mathrm{X}$ together" [5][51][52]. This concept differs from cooperation based on individual goals and personal intentions, which can be expressed as "I intend to do X" and is often applied in more traditional theories, such as theories of reasoned action or planned behavior [5].

Drawing on social antecedents such as social identity [3][4][49], group norms [8][49] or joint commitment [40][46], we-intention theory has proven to be a promising approach for investigating contribution and participation behavior in cooperative virtual settings.

Apart from the above-mentioned antecedents, it has been proposed that we-intentions may root from altruistic sentiment [2][50]. However, the lack of empirical research has so far left us in the dark whether altruism may affect the formation of we-intentions. In addition, it remains unclear how certain design features in a system may stimulate altruism. Therefore, this study seeks to explore whether cooperative game features can invoke altruism and if altruism leads to the formation of we-intentions.

\subsection{Altruism}

Altruistic action is usually described as helping behavior [6][11][31] and a perceived enjoyment for doing so [10][32]. In virtual communities, seemingly altruistic action can be observed on various accounts: people participate in online fundraisings, provide answers to questions of strangers online, contribute knowledge to wiki sites or share open source software solutions with the public [4][17][57].

In scientific literature, the concept of altruism has been subject to some controversy, with the main argument being that even when an apparent altruistic behavior (e.g. helping others) is performed, it may in fact be a product of a self-serving need or driven by personal goals that are unrelated to the desire to help others [6][11]. Such goal structures can be regarded as independent (I-goals). Pioneers in the field therefore stress that altruism should be examined in accordance with the underlying goal structures of people who engage in helping behavior [6].

Essentially, helping on an altruistic account is broadly regarded as involving a perceived enjoyment for doing so, and provided the help occurred based on an individual's ultimate goal to increase the welfare of others [6][32]. It has also been suggested that altruism may especially arise within groups with which individuals identify, leading to a "we"-perspective [47]. In the realm of we-intention, identification with the group is largely regarded as an important antecedent [3][8][49]. Moreover, it has been suggested that altruism may occur within an inner group, being manifested by means of an individual's goal (i.e. we-goal) to help and support group members [2].

One particular context in which altruistic action seemingly occurs naturally is multiplayer online games. Several studies devoted to investigating prosocial patterns in games offer that players frequently receive help or favors within games, often without the obligation to reciprocate the help [42][55], and that playing prosocial games can increase prosocial thoughts and helping behavior [14][19]. 
Games such as Pokémon Go, Ingress, Minecraft and World of Warcraft have become tremendously popular over the recent years, connecting an immense number of people who socially interact with each other on a daily basis. Therefore, it is not surprising that more and more researchers and practitioners seek to understand how the social potential of games and gamification could be transferred to workplace environments (e.g. [28][54]), crowdsourcing networks or other online communities that rely on cooperative interaction (e.g. [37][38][40]).

\section{Hypotheses and research model}

\subsection{Cooperative game features}

Many games, especially multiplayer games, rely on social interaction and cooperative play. To achieve cooperative interaction, games usually specify certain rules that set the cooperative frame, allow for trade and communication, define mutual goals, create situations in which players depend on each other or in which skills of certain player roles complement each other [15][40][42]. As suggested by a number of previous studies, collective intentions and cooperative action in games are essentially enabled and facilitated through the exposure of cooperative game patterns [15][40]. We therefore hypothesize:

H1a. Engagement with cooperative game features positively relates to we-intentions.

Prosocial game patterns and playing cooperatively have previously been suggested to give rise to prosocial motives [14][19][41][42]. Games and gamification have long been argued to yield powerful mechanisms to increase intrinsic motivation [23][36][59] and engaging in altruistic action has been proposed to be intrinsically fulfilling in the sense that people enjoy helping others [57]. Team features, virtual gift giving, and other features of cooperative nature have been associated with giving rise to altruistic sentiment and helping behavior in games [41][42][53]. Accordingly, we propose that the engagement with cooperative game features is positively associated with altruism in games.

H1b. Engagement with cooperative game features positively relates to altruism.

As suggested by theories of goal setting, cooperative design such as interdependent roles, common challenges or tasks as well as shared benefits or group rewards, are all ways to create mutually held goals [48]. Games are notorious for being capable of addressing all of the above. They are motivating mutual goals by means of cooperative game features [15][40]. We therefore hypothesize that cooperative game features invoke we-goals.

H1c. Engagement with cooperative game features positively relates to we-goals.

To continue the assertions above, if the engagement with cooperative game features mainly benefits the group instead of oneself, it seems a logical assumption that such cooperative actions are likely to be carried out in support of the group goals rather than for strictly personal goals. This assumption is in line with suggestions from previous studies devoted to the design of cooperative systems by utilizing cooperative game features [39][40]. These studies suggest that cooperative features invoke shared goals whereas features of individualistic nature (e.g. badges, levels, etc.) invoke personal independent goals. Accordingly, we propose that engagement with cooperative game features is only associated with we-goals and lack association with I-goals.

H1d. Engagement with cooperative game features does not relate to I-goals.

\subsection{Altruism}

As outlined in the theory section, the notion of altruism is closely linked with motivations to help others and a feeling of enjoyment for doing so. Altruism is therefore largely conceptualized as a perceived enjoyment for helping others [10][27][32], which we adopted for this study. As proposed by altruism theory, it is vital to consider the underlying goal structures of people who engage in altruistic action [6]. Altruism theory suggests that altruistic motivations should essentially stem from the ultimate goal of an individual to increase the welfare of others or of an inner group [2][6]. People who help others based on altruistic sentiment should thus have cooperative goal structures (wegoals). Based on this notion, we propose that altruism is positively associated with we-goals.

H2a. Altruism positively relates to we-goals.

Altruism theory further suggests that if an individual helps another person in order to gain a personal benefit, the helping behavior hardly emerged from an altruistic mindset [6][11]. In this case, the individual rather followed an independent goal (i.e. I-goal), as he or she did not intent to increase the welfare of others but rather to achieve a personal goal that is unrelated to the group's welfare. The altruistic idiosyncrasy to en- 
joy helping others is therefore not very likely to be associated with invoking I-goals. Respectively, we propose:

H2b. Altruism does not relate to I-goals.

Altruism as an expression of enjoyment for helping others [10][32] has previously been found to positively affect engagement in collective action [27][32][56][57] and according to several renowned scholars in the field, collective action is more fittingly explained by drawing on we-intention theory as compared to more conventional adoption theories that focus on individual intentions [3][52]. In light of these suggestions, we expect altruism to be positively related with weintention and propose the following hypothesis:

H2c. Altruism positively relates to we-intention.

\subsection{Goal structures}

Goal-setting theory offers that goals can be set collectively [34] and collective goals are widely recognized for invoking collective intentions and cooperative behavior [50][51][52]. We-intention theory pro- vides ample theoretical support with respect to the role of collective goals for invoking we-intentions. Previous research suggests that cooperatively held values and goals are captured through social identification and group norms, leading to the formation of we-intentions [4][8][49]. These suggestions are articulated at the core of we-intention theory via the argumentation that weintentions commonly emerge in situations where individuals aim at achieving joint goals [52]. On the basis of these theoretical suggestions, we posit:

H3a. We-goals positively relate to we-intentions.

A fundamental distinction between we-intentions and conventional personal intentions is harbored within individuals different goal structures. While weintentions are said to be invoked by we-goals, individual intentions are said to be invoked by personal commitment and personal goals [5][52]. This means that we-intentions should be explained by we-goals whereas I-goals should play an inferior role for explaining we-intentions. Hence, we suggest:

H3b. I-goals do not relate to we-intentions.

\section{Figure 1: Research model and results}

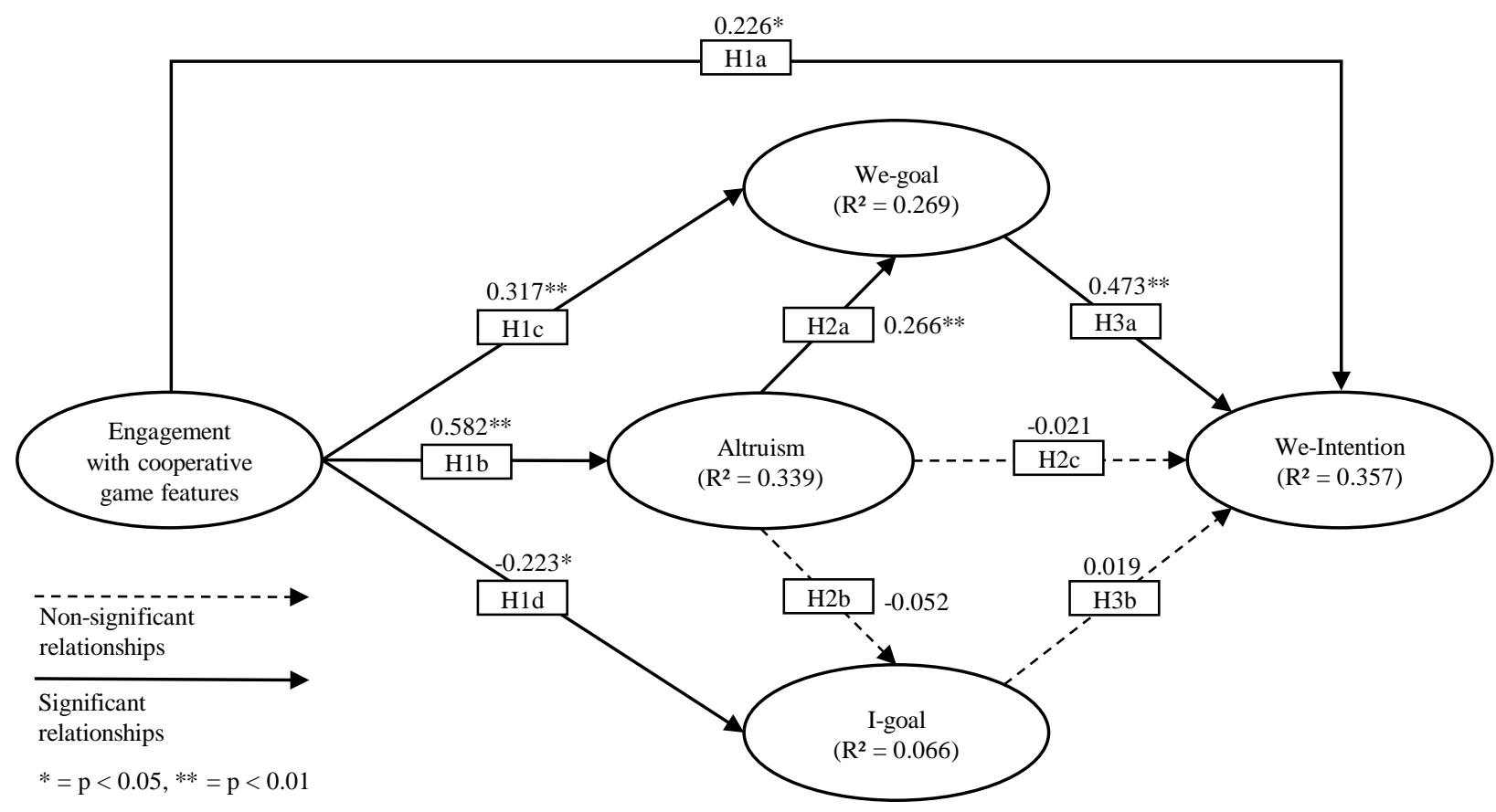




\section{The empirical study}

\subsection{Data}

The data for this study was collected from users of Ingress. Ingress is a popular augmented reality game and trailblazer for games such as Pokémon Go or Harry Potter Wizards Unite. Using a mobile phone, players of Ingress move around the real world via a map, which extends the real environment with virtual objects. Players join one of two teams (factions), each aiming at taking over virtual portals and connecting them to span fields with the goal to cover more space with said fields as the opposing team. The game works via inter-group competition but also significantly relies on intra-group cooperation. Since the game supports cooperative play via specifying shared goals and requiring players to support each other, it is suitable for the purpose of our study.

In terms of recruiting participants for our survey, we turned to Ingress communities within social networking websites and forums where we posted the questionnaire. The survey ran for approximately five months. A number of 206 participants at the average age of 34.6 (30.1\% female and 69.9\% male) from 15 different countries completed the survey. The majority of respondents (68.4\%) stated to play Ingress multiple times a day. $26.2 \%$ of respondents further stated to have played Ingress for less than a year whereas 29.1 $\%$ between 1 and 2 years, $26.2 \%$ between 2 and 3 years, and $18.4 \%$ three years and longer.

\subsection{Measurement}

The items for measuring altruism, I-goals, we-goals and we-intentions were all adopted from prior studies (see appendix Table 1). For cooperative game features the items were newly developed in correspondence to the following procedure: In a first step, all necessary information about the game, gameplay and game features were gathered by available documents and descriptions about the game as well as by playing the game. In addition, we conducted eight semi-structured telephone interviews with Ingress players, all of which had been playing the game for a minimum of six months. By drawing on the classification framework by Morschheuser et al. [39] and using a 5-point Likert scale (strongly disagree - strongly agree), the interviewees were asked to what degree they affirm each game feature to have individualistic, cooperative or competitive traits. The results from the interviews are shown in the appendix in Table 2. Some features were perceived as both cooperative and competitive. For the features in question, we focused on the cooperative aspects in our operationalization of the survey items. The final items measure the engagement as well as importance of cooperative game features and were modeled in a formative manner, since they are not exchangeable and since the effects stem from a player's use and perceived importance of the features. The other constructs were all arranged in a reflective manner.

To test the appropriateness of the survey scales, a pre-study was conducted [21] with 110 users, revealing a high validity of the items and requiring only minor adjustments concerning the newly developed construct.

\subsection{Validity and reliability}

The research model was tested via structural equation modeling (component-based PLS-SEM) in SmartPLS 3 [44]. Using structural equation modeling is commonplace for testing causal effects in complex models with several dependent and independent variables [35]. We chose to test the model via componentbased SEM, which is regarded preferable to covariance-based SEM when it comes to testing predictive studies [1] and for research models that consist of both formative and reflective measures [35]. We assessed convergent validity by reflecting on composite reliability (CR) as well as average variance extracted (AVE). All measures were acceptable, exceeding the thresholds of 0.7 for CR and 0.5 for AVE [16] (see appendix Table 3). For assessing discriminant validity, we verified that each item had the highest loading with its corresponding latent variable instead of with any cross loadings [20].

In conclusion, validity and reliability of the measurement model is supported, given that all criteria for convergent as well as discriminant validity are met. Moreover, several criteria for lower bounds of sample size for PLS-SEM are satisfied [1][9].

\subsection{Results}

As presented in Figure 1, the research model accounts for $35.7 \%$ of the variance for we-intention, $33.9 \%$ of altruism, $26.9 \%$ of we-goal and $6.6 \%$ of Igoal.

Significant positive relationships could be observed between engagement with cooperative game features and we-intention $(\beta=0.226, \mathrm{p}<0.05)$, altruism $(\beta=$ $0.582, \mathrm{p}<0.01)$ and we-goal $(\beta=0.317, \mathrm{p}<0.01)$. These results are in support of $\mathrm{H} 1 \mathrm{a}-\mathrm{H} 1 \mathrm{c}$. The relationship between engagement with cooperative game features and I-goal is significantly negative $(\beta=-0.223, p$ $<0.05)$. H1d could not be confirmed, since we hypothesized a non-significant relationship between these variables. However, this result still supports our gen- 
eral understanding that engagement with cooperative game features do not invoke I-goals. Interestingly, it rather seems that cooperative game features even negatively influence the emergence of I-goals.

Further, H2a is supported due to the significant positive relationship between altruism and we-goal $(\beta$ $=0.266, \mathrm{p}<0.01)$. The relationship between altruism and I-goal is non-significant $(\beta=-0.052, \mathrm{p}>0.05)$, which was expected and thus, $\mathrm{H} 2 \mathrm{~b}$ is supported. Against our expectation, altruism has no significant direct relationship with we-intention $(\beta=-0.021, \mathrm{p}>$ $0.05)$. H2c could therefore not be supported, however, we-goal served as a partial mediator for this relationship $(\beta=0.126, \mathrm{p}<0.01)$.

As hypothesized, the relationship between we-goal and we-intention turned out to be positive $(\beta=0.473$, $p$ $<0.01$ ), and also in consensus with our expectation, no significant relationship between I-goal and weintention could be observed $(\beta=0.019, \mathrm{p}>0.05)$. H3a and $\mathrm{H} 3 \mathrm{~b}$ could therefore each be supported.

An overview of the results can be found in the appendix in Table 4.

\section{Discussion}

The aim of this study was to empirically investigate how the engagement with cooperative game features relates to the emergence altruism and whether altruism may be responsible for invoking we-intentions. To answer this question, we collected data via a survey from users of the augmented reality game Ingress $(n=206)$.

Our findings suggest that interaction with cooperative game design features can give rise to altruism in games. Contributing to the welfare of others in games seems to be intrinsically fulfilling for players, given they are rewarded with a feeling of enjoyment for their prosocial in-game behavior. According to altruism theory, this is a natural consequence of helping [6] and what's more, it adds to our understanding pertaining to the different facets by which games or features of games may give rise to intrinsically fulfilling outcomes [36][59].

The results further indicate that altruism can invoke we-intentions via we-goals. Due to scarce empirical analysis supporting this theorization rooting from weintention research [2][50], this result presents a vital contribution to our understanding regarding how weintentions and thus cooperation can emerge. To comply with suggestions from altruism theory that the underlying goal structures of people should be examined more closely when investigating the notion of altruism [6], we included the concept of I-goal as a counterpart to we-goal in our research model. Altruism was found to promote we-goals whereas I-goals are not incited, which is in line with the theoretical suggestions in terms of the underlying goal structure of altruism [6].

Pertaining to the relationships between cooperative game features and goal structures, we found that cooperative types of game features can invoke we-goals while the formation of I-goals is negatively affected. This result supports the notion that cooperative game features should invoke shared goals whereas independent goals are invoked by individualistic game features [39]. In accordance with propositions regarding the different notions of individual and collective intentions, our results also support that we-intentions are invoked by we-goals whereas I-goals are unrelated to we-intentions [5][52]. These findings are interesting because engagement in cooperative behavior in games may also stem from striving after personal goals and achievements, such as levelling up, earning points and badges, or moving to the top of a leaderboard. In these cases, group contributions are carried out due to selfcentered rather than altruistic motivations [6]. Thus, while cooperative behavior may be achieved this way, it seems that the exposure of game features that invoke I-goals do in fact not motivate cooperative mindsets. On the other hand, our results indicate that cooperative game design has the ability to engage users in cooperative behavior because they value the group goals and value helping others, which may ultimately result in sincerer and more reliable forms of cooperation in games, namely cooperation based on we-intentions.

There has also been much discussion about the effects of games on behaviors after their use. While majority of studies investigated the negative behavioral outcomes of playing violent games, recent studies have also examined the positive behavioral outcomes of playing prosocial games. Remarkably, these studies found that games can have positive effects on prosocial behavior, teambuilding, cohesion and team performance in succession to playing (e.g. [19][28]). Therefore, even if it may pose a greater challenge, we recommend designing systems with the objective to achieve full-blown cooperation by addressing altruistic motivations and we-intentions of individuals as compared to relying on cooperation based on individual motives and goals.

Interestingly, our results also indicate that the exposure of cooperative game features can directly influence we-intentions, thereby adding generalizability to previous studies which offer that cooperative game design supports collective action in games [15][40].

\subsection{Practical implications for gamification}

Several implications can be derived from this study which may be of value for practitioners seeking to in- 
crease altruistic action as well as cooperation or collaboration by gamification:

Design implication 1: The setting of goals is a wellknown gamification design feature [12][24]. For systems that aim at increasing cooperation, we recommend focusing more on motivating goals that benefit the group over goals that benefit strictly oneself. Our results show that in the presence of cooperative game features cooperative goals emerge, and this may even lead to the detriment of personal goals. This is a desirable outcome in most cooperative settings, however, it also raises the concern that vice versa features which invoke I-goals may interfere with the emergence of we-goals. Accordingly, we suggest that blending features that address different goal structures should be regarded with care. It would especially be beneficial to attempt aligning personal goals with group goals in order to increase prosocial activity and simultaneously reduce the risk of harming the emergence of altruistic motivation and collective intentions.

Design implication 2: According to our results, engagement with cooperative features can lead to the altruistic and intrinsically rewarding perception of enjoyment for helping others. We therefore recommend enriching systems with elements that motivate mutual support and let users express their goodwill as well as enable them to experience enjoyment for helping or contributing to the welfare of others.

Design implication 3: We further found that the exposure of cooperative game features can directly influence we-intentions. Thus, in order to give rise to collective intentions, we recommend shifting the focus of traditional gamification features such as rewards, challenges, achievements and so forth, from an individual level to a group level (e.g. group rewards, group challenges, group achievements, etc.).

\subsection{Future research}

With this study we provided a doorway for more research on the concepts of altruism and we-intention in the domain of game and gamification research.

We provided empirical support of the theoretical suggestion that altruism may play a central role for the emergence of we-intentions [2][50]. However, cooperation and seemingly altruistic action such as helping others can also root from personal intentions, personal goals and egoistic motivations [5][6][11][52]. An intriguing question that surfaced from this study is, if egoism as a counterpart to altruism may be responsible for invoking I-goals and personal intentions. Future studies could extend our research by simultaneously investigating these concepts. This would broaden our understanding about the conceptual differences of weintentions and personal intentions as well as to whether egoism or altruism is the main driver for cooperation in games.

Finally, we call for more studies to differentiate between the conceptual schemes of we-intention and personal intentions, as we believe that it would result in more accurate explanations to why people engage in games and gamification services.

\section{References}

[1] Anderson, J. C., \& Gerbing, D. W. (1988). Structural equation modeling in practice: A review and recommended two-step approach. Psychological Bulletin, 103(3), 411.

[2] Bagozzi, R. P. (2000). On the concept of intentional social action in consumer behavior. Journal of Consumer Research, 27(3), 388-396.

[3] Bagozzi, R. P., \& Dholakia, U. M. (2002). Intentional social action in virtual communities. Journal of Interactive Marketing, 16(2), 2-21.

[4] Bagozzi, R. P., \& Dholakia, U. M. (2006). Open source software user communities: A study of participation in Linux user groups. Management Science, 52(7), 1099-1115.

[5] Bagozzi, R. P., \& Lee, K.-H. (2002). Multiple routes for social influence: The role of compliance, internalization, and social identity. Social Psychology Quarterly, 226-247.

[6] Batson, C. D., \& Shaw, L. L. (1991). Evidence for altruism: Toward a pluralism of prosocial motives. Psychological Inquiry, 2(2), 107-122.

[7] Bui, A., Veit, D., \& Webster, J. (2015). Gamification - a novel phenomenon or a new wrapping for existing concepts? In Proceedings of the 36th international conference on information systems - ICIS'15, Fort Worth, Texas, USA, 1-21.

[8] Cheung, C. M. K., Chiu, P.-Y., \& Lee, M. K. O. (2011). Online social networks: Why do students use facebook? Computers in Human Behavior, 27(4), 1337-1343.

[9] Chin, W. W. (1998). The partial least squares approach to structural equation modeling. Modern Methods for Business Research, 295(2), 295-336.

[10] Cho, H., Chen, M., \& Chung, S. (2010). Testing an integrative theoretical model of knowledge-sharing behavior in the context of Wikipedia. Journal of the American Society for Information Science and Technology, 61(6), 1198-1212.

[11] Cialdini, R. B. (1991). Altruism or egoism? That is (still) the question. Psychological Inquiry, 2(2), 124-126.

[12] Deterding, S., Dixon, D., Khaled, R., \& Nacke, L. (2011). From game design elements to gamefulness: defining gamification. In Proceedings of the 15th International Academic MindTrek Conference: Envisioning Future Media Environments, Tampere, Finland, ACM, 9-15.

[13] Deutsch, M. (1949). A theory of co-operation and competition. Human Relations, 2(2), 129-152.

[14] Dolgov, I., Graves, W. J., Nearents, M. R., Schwark, J. D., \& Volkman, C. B. (2014). Effects of cooperative gaming and avatar customization on subsequent spontaneous helping behavior. Computers in Human Behavior, 33, 49-55. 
[15] El-Nasr, M. S., Aghabeigi, B., Milam, D., Erfani, M., Lameman, B., Maygoli, H., et al. (2010). Understanding and evaluating cooperative games. In Proceedings of the 28th international conference on Human factors in computing systems - CHI'10, Atlanta, Georgia, USA, 253-262.

[16] Fornell, C., \& Larcker, D. F. (1981). Evaluating structural equation models with unobservable variables and measurement error. Journal of Marketing Research, 18(1), 39-50.

[17] Gleasure, R., \& Feller, J. (2016). Does heart or head rule donor behaviors in charitable crowdfunding markets? International Journal of Electronic Commerce, 20(4), 499-524.

[18] Greitemeyer, T., \& Mügge, D. O. (2014). Video games do affect social outcomes: A meta-analytic review of the effects of violent and prosocial video game play. Personality and Social Psychology Bulletin, 40(5), 578-589.

[19] Greitemeyer, T., \& Osswald, S. (2011). Playing prosocial video games increases the accessibility of prosocial thoughts. The Journal of Social Psychology, 151(2), 121128.

[20] Hair, J. F., Ringle, C. M., \& Sarstedt, M. (2011). PLSSEM: Indeed a silver bullet. Journal of Marketing Theory and Practice, 19(2), 139-152.

[21] Hair, J. F., Black, W. C., Babin, B. J., \& Anderson, R. E. (2014). Multivariate data analysis: Pearson new international edition. Essex: Pearson Education Limited.

[22] Hamari, J. (2019). Gamification. Wiley Blackwell Encyclopedia of Sociology (in press).

[23] Hamari, J., \& Koivisto, J. (2015). Why do people use gamification services? International Journal of Information Management, 35(4), 419-431.

[24] Hamari, J., Koivisto, J., \& Sarsa, H. (2014). Does gamification work? - A literature review of empirical studies on gamification. In Proceedings of the 47th Hawaii international conference on system sciences - HICSS'14, Waikoloa, HI, USA, 3025-3034.

[25] Johnson, D. W., \& Johnson, R. T. (1989). Cooperation and competition: Theory and research. Edina, MN, US: Interaction Book Company.

[26] Johnson, D. W., \& Johnson, R. T. (1996). Cooperation and the use of technology. Handbook of Research for Educational Communications and Technology: a Project of the Association for Educational Communications and Technology, 1017-1044.

[27] Kankanhalli, A., Tan, B. C. Y., \& Wei, K.-K. (2005). Contributing knowledge to electronic knowledge repositories: an empirical investigation. MIS Quarterly, 113-143.

[28] Keith, M. J., Anderson, G., Gaskin, J., \& Dean, D. L. (2018). Team Video Gaming for Team Building: Effects on Team Performance. AIS Transactions on Human-Computer Interaction, 10(4), 205-231.

[29] Koivisto, J., \& Hamari, J. (2019). The rise of motivational information systems: A review of gamification research. International Journal of Information Management, 45, 191-210.

[30] Leclercq, T., Poncin, I., \& Hammedi, W. (2017). The Engagement Process During Value Co-Creation: Gamification in New Product-Development Platforms. International Journal of Electronic Commerce, 21(4), 454-488.

[31] Lehmann, L., \& Keller, L. (2006). The evolution of cooperation and altruism-a general framework and a classifi- cation of models. Journal of Evolutionary Biology, 19(5), 1365-1376.

[32] Lin, H.-F. (2007). Effects of extrinsic and intrinsic motivation on employee knowledge sharing intentions. Journal of Information Science, 33(2), 135-149.

[33] Liu, D., Li, X., \& Santhanam, R. (2013). Digital Games and Beyond: What Happens When Players Compete. MIS Quarterly, 37(1), 111-124.

[34] Locke, E. A., \& Latham, G. P. (2006). New directions in goal-setting theory. Current Directions in Psychological Science, 15(5), 265-268.

[35] Lowry, P. B., \& Gaskin, J. (2014). Partial least squares (PLS) structural equation modeling (SEM) for building and testing behavioral causal theory: When to choose it and how to use it. IEEE Transactions on Professional Communication, 57(2), 123-146.

[36] Malone, T. W. (1981). Toward a theory of intrinsically motivating instruction. Cognitive Science, 5(4), 333-369.

[37] Morschheuser, B., Hamari, J., Koivisto, J., \& Maedche, A. (2017). Gamified crowdsourcing: Conceptualization, literature review, and future agenda. International Journal of Human-Computer Studies, 106, 26-43.

[38] Morschheuser, B., Hamari, J., \& Maedche, A. (2018). Cooperation or competition - When do people contribute more? A field experiment on gamification of crowdsourcing. International Journal of Human-Computer Studies.

[39] Morschheuser, B., Maedche, A., \& Walter, D. (2017). Designing cooperative gamification: Conceptualization and prototypical implementation. In Proceedings of the 20th ACM conference on computer-supported cooperative work and social computing - CSCW'17, Portland, OR, USA, 24102421.

[40] Morschheuser, B., Riar, M., Hamari, J., \& Maedche, A. (2017). How games induce cooperation? A study on the relationship between game features and we-intentions in an augmented reality game. Computers in Human Behavior, 77, 169-183.

[41] Nakajima, T., \& Lehdonvirta, V. (2013). Designing motivation using persuasive ambient mirrors. Personal and Ubiquitous Computing, 17(1), 107-126.

[42] Nardi, B.,Harris, J.: Strangers and Friends: Collaborative Play in World of Warcraft. In: Proceedings of CSCW 2006, ACM, New York, (2006), 149-138

[43] Peng, W., Lee, M., \& Heeter, C. (2010). The effects of a serious game on role-taking and willingness to help. Journal of Communication, 60(4), 723-742.

[44] Ringle, C. M., Wende, S., \& Becker, J.-M. (2015). SmartPLS 3. Boenningstedt: SmartPLS GmbH, http://www. smartpls.com.

[45] Sanders, N. R. (2007). An empirical study of the impact of e-business technologies on organizational collaboration and performance. Journal of Operations Management, 25(6), 1332-1347.

[46] Shen, A. X. L., Lee, M. K. O., Cheung, C. M. K., \& Chen, H. (2009). An investigation into contribution IIntention and we-intention in open web-based Encyclopedia: Roles of joint commitment and mutual agreement. In Proceeding of the 13th international conference on information systems e ICIS'09, Phoenix, Arizona, USA, 1-7.

[47] Simon, H. A. (1993). Altruism and economics. The American Economic Review, 83(2), 156-161. 
[48] Tjosvold, D. (1998). Cooperative and competitive goal approach to conflict: Accomplishments and challenges. Applied Psychology, 47(3), 285-313.

[49] Tsai, H.-T., \& Bagozzi, R. P. (2014). Contribution behavior in virtual communities: cognitive, emotional, and social influences. MIS Quarterly, 38(1), 143-164.

[50] Tuomela, R. (1995). The importance of us: A philosophical study of basic social notions. Stanford, CA: Stanford University Press.

[51] Tuomela, R. (2006). Joint Intention, We-Mode and I-Mode. Midwest Studies in Philosophy, 30(1), 35-58.

[52] Tuomela, R., \& Miller, K. (1988). We-intentions. Philosophical Studies, 53(3), 367-389.

[53] Velez, J. A., \& Ewoldsen, D. R. (2013). Helping behaviors during video game play. Journal of Media Psychology.

[54] Vesa, M., Hamari, J., Harviainen, J. T., \& Warmelink, H. (2017). Computer games and organization studies. Organization Studies, 38(2), 273-284.
[55] Wang, C.-C., \& Wang, C.-H. (2008). Helping others in online games: Prosocial behavior in cyberspace. CyberPsychology \& Behavior, 11(3), 344-346.

[56] Wasko, M. M., \& Faraj, S. (2000). "It is what one does": why people participate and help others in electronic communities of practice. The Journal of Strategic Information Systems, 9(2-3), 155-173.

[57] Wasko, M. M., \& Faraj, S. (2005). Why should I share? Examining social capital and knowledge contribution in electronic networks of practice. MIS Quarterly, 35-57.

[58] Wong, A., Tjosvold, D., \& Yu, Z. Y. (2005). Organizational partnerships in China: self-interest, goal interdependence, and opportunism. Journal of Applied Psychology, 90(4), 782.

[59] Xi, N., \& Hamari, J. (2019). Does gamification satisfy needs? A study on the relationship between gamification features and intrinsic need satisfaction. International Journal of Information Management, 46, 210-221.

\section{Appendix}

\section{Table 1: Measurement items}

We-intention

Source: [46][49]

1) I intend that our group (i.e. myself and the group that I identified before) play Ingress together sometime during the next 4 weeks.

2) We (i.e., I and the group that I identified before) intend to play Ingress together sometime during the next 4 weeks.

3) We (i.e., I and the group that I identified before) plan to play Ingress together sometime during the next 4 weeks. We-goal

1) The group (I identified before) and I "swim or sink" together. Source: [46][58]

2) The members of the group (I identified before) and I seek compatible goals.

3) We (i.e., I and the group that I identified before) all know that all members are jointly committed to performing their parts of the common tasks.

I-goal

1) The members of the group (I identified before) and I "do our own thing".

2) The members of the group (I identified before) and I pursue our own independent goals.

3) The members of the group (I identified before) are most concerned about what they accomplish when playing by themselves.

Altruism Source: [32][53][56]

1) I like helping other members of the group I mentioned before in Ingress.

2) It feels good to help other members of the group I mentioned before in Ingress.

3) I enjoy helping other members of the group I mentioned before in Ingress.

4) Assisting members of the group I identified before in Ingress is pleasurable.

Cooperative game features

Newly developed formative measure

1) How often do you upgrade portals of other players (Upgrade = deploy mods, deploy additional resonators, upgrade resonators to higher level)

2) How often do you recharge resonators of other players?

3) How often do you communicate with other players via chat?

4) How often do you create control fields, in order to obtain Mind Units (MU)?

5) How often do you participate in XM Anomalies? (for the sake of playing Ingress together with other people)

6) How often do you participate in Mission Days? (for the sake of playing Ingress together with other people)

7) How often do you participate in First Saturday (FS) events?

8) How often do you look at the faction's progress during a cycle?

9) How important is it to you to upgrade portals of other players? (Upgrade = deploy mods, deploy additional resonators, upgrade resonators to higher level)

10) How important is it to you to recharge resonators of other players?

11) How important is it to you to communicate with other players via chat?

12) How important is it to you to create control fields, in order to obtain Mind Units (MU)?

13) How important are XM Anomalies to you? (with regard to playing Ingress with other people)

14) How important are Mission Days to you? (with regard to playing Ingress with other people)

15) How important are First Saturday (FS) events to you?

16) How important is to you to see the faction's progress during a cycle? 
Table 2: Ingress feature categorization

\begin{tabular}{|c|c|c|c|}
\hline Ingress game feature & Individualistic & Cooperative & Competitive \\
\hline Action points & $\mathrm{X}$ & & \\
\hline Agent level & $\mathrm{X}$ & & \\
\hline Agent stats & $\mathrm{X}$ & & \\
\hline Medals & $\mathrm{X}$ & & \\
\hline Mission Badges & $\mathrm{X}$ & & \\
\hline Personal avatar & $\mathrm{X}$ & & \\
\hline Power cubes & $\mathrm{X}$ & & \\
\hline Playing missions & $\mathrm{X}$ & & \\
\hline Mission days & $(\mathrm{x})$ & $\mathbf{X}$ & \\
\hline Factions & & $\mathbf{X}^{*}$ & \\
\hline Mind units & & $\mathbf{X}^{*}$ & \\
\hline Deploy resonators & & $\mathbf{X}^{*}$ & \\
\hline Recharge resonators & & $\mathbf{X}^{*}$ & \\
\hline COMM (in-game chat) & & $\mathbf{X}$ & \\
\hline First Saturday events & & $\mathbf{X}^{*}$ & \\
\hline XM Anomalies & & $\mathbf{X}^{*}$ & \\
\hline Mods & & $\mathbf{X}^{*}$ & \\
\hline Takeover portals & & $\mathbf{X}^{*}$ & \\
\hline Upgrade portals & & $\mathbf{X}^{*}$ & \\
\hline Checkpoints and cycles & & $\mathbf{X}^{*}$ & \\
\hline Attacking portals & & & $\mathrm{X}$ \\
\hline Weapons & & & $\mathrm{X}$ \\
\hline Hacking portals & $\mathrm{C}$ & $\mathrm{C}$ & $\mathrm{C}$ \\
\hline
\end{tabular}

$\mathrm{X}=$ primary perceived category of the game feature.

$(\mathrm{x})=$ secondary perceived category of the game feature, A minority of experts perceived this feature as part of the category. $*$ = features that were perceived as having both competitive traits (on an intergroup level) as well as cooperative traits (on an intragroup level). For such cooperative-competitive features, we carefully identified the cooperative aspects before developing the corresponding survey items.

$\mathrm{C}=$ features that were perceived as core game mechanics of the game. Thus, no clear assignment to one of the features categories could be made.

Table 3: Validity and reliability

\begin{tabular}{|l|l|l|l|l|l|l|l|}
\hline & AVE & CR & CGF & Altruism & We-goal & I-goal & We-intention \\
\hline CGF & n/a & n/a & n/a & & & & \\
\hline Altruism & 0.695 & 0.901 & 0.582 & $\mathbf{0 . 8 3 4}$ & & & \\
\hline We-goal & 0.581 & 0.806 & 0.472 & 0.450 & $\mathbf{0 . 7 6 2}$ & & \\
\hline I-goal & 0.558 & 0.784 & -0.253 & -0.182 & -0.165 & $\mathbf{0 . 7 4 7}$ & \\
\hline We-Intention & 0.884 & 0.958 & 0.432 & 0.320 & 0.567 & -0.113 & $\mathbf{0 . 9 4 0}$ \\
\hline
\end{tabular}

CGF $=$ Cooperative game features

Table 4: Results

\begin{tabular}{|l|l|c|c|c|c|}
\hline Independent variable & Dependent variable & $\boldsymbol{\beta}$ & CI95LO & CI95 HI & p \\
\hline Cooperative game features & Altruism & 0.582 & 0.470 & 0.700 & 0.000 \\
\hline & We-goals & 0.317 & 0.195 & 0.558 & 0.001 \\
\hline & I-goals & -0.223 & -0.443 & -0.029 & 0.042 \\
\hline & We-intention & 0.226 & 0.082 & 0.484 & 0.035 \\
\hline Altruism & We-goal & 0.266 & 0.024 & 0.398 & 0.006 \\
\hline & I-goal & -0.052 & -0.205 & 0.194 & 0.598 \\
\hline & We-intention & -0.021 & -0.245 & 0.143 & 0.833 \\
\hline We-goal & We-intention & 0.473 & 0.314 & 0.568 & 0.000 \\
\hline I-goal & We-intention & -0.095 & 0.162 & 0.772 \\
\hline
\end{tabular}

$\beta=$ standard regression coefficients, $\mathrm{CI}=$ Confidence interval 